\title{
Factor Analysis of Competency Based Trained Graduates of Polytechnic/Technical Universities in Ghana
}

\author{
Edwin Mends-Brew \\ Joseph Dadzie \\ Ben Apau Dadson \\ Martin Owusu Amoamah
}

Department of Mathematics \& Statistics, Accra Technical University, Accra, Ghana

Doi: 10.19044/esj.2017.v13n36p282 URL:http://dx.doi.org/10.19044/esj.2017.v13n36p282

Abstract

Higher Education, particularly Polytechnic education which sits at the apex of Technical and Vocational Education and Training (TVET) has undergone a great deal of transformation over the last several years. Polytechnic education was incorporated into the educational system with the primary objective of providing employable skills needed to propel growth in the various sectors of the economy. Therefore, Technical and vocational education and training (TVET) plays a significant role for the socioeconomic development of any country to meet the challenges of skilled labour in the global market and the ever widening digital divide coupled with the development of a knowledge-based economy. Competency Based Training (CBT) which entails the practical aspect of technical and vocational training relates theoretical knowledge to actual practice. For more than a decade, this has been part of the curricula of polytechnic education in Ghana as an alternative method of delivery to equip students with hands-on experience and competencies required in the job market (Salifu et al, 2010). CBT provides an improved form of delivery centered on the integration of acquired knowledge, professional and practical skills and attitude, coupled with a market-driven focus on the student (Afeti et al, 2003). Having churned out graduates through the CBT approach, it is imperative to assess the readiness of these graduates for the job market. It is against this background that the study was conducted to do a 'Need Analysis' of these graduates. A total of 55 graduates in two polytechnics were used for the study. The study sought to examine the relative influence of factors influencing career choices of these graduates having been trained through the competency based mode of Teaching and delivery. Factor analysis of ratings of importance of a 
number of job creation characteristics were used. These results were used to build scales of importance and preference, which were then tested with other variables in a predictive model in which the dependent variable was the decision to be self-employed or to be engaged for employment by third parties upon completion of their respective programmes. The following were found to influence decisions; work-related concerns, gender, age, financial support, family background and internship placements. The results also showed that most of the graduates exhibited that sense of inadequacy towards becoming entrepreneurs or starting their own businesses.

Keywords: Factor Analysis, Predictive model, Competency Based Training, Scales

\section{Introduction}

Education is a phase of the social process which is fostered by society for the purpose of fitting its members for life in a group. Education is thus concerned with the enhancement and transmission of culture. It seeks to enhance by furthering the process through all of its social agencies, but particularly through the school (Skinner, 1945). Education has become a very significant system for human development in any society. Higher Education, particularly Polytechnics sit at the apex of the Technical and Vocational Education and Training (TVET) spectrum as institutions of higher learning. Thus, the rationale of polytechnic education was essentially, to produce the critical core of middle-level manpower for the country with special emphasis on the acquisition of hands-on practical and entrepreneurial skills to train career-focused technical workforce required to meet the needs of the labour market. In addition, Polytechnic education in Ghana seeks to provide alternative opportunities for a segment of the youth population who aspire to develop careers by hands-on learning at the tertiary level (Afeti 2003; Agodzo, 2005). In view of the fact that, monumental changes propelling globalization had all been achieved largely as a result of remarkable developments in skilled human capital in the areas of science and technology, Polytechnics are engaged in a sustained and continuous process of optimizing the quality of their products so as to enhance their readiness for the job market. Consequently, the response to these sustained efforts, prompted an urgent need to improve the curricula, teaching methods and infrastructure to increase the relevance of skills training in Ghana, particularly the need to reform the curricula and its delivery brought about the introduction of the Competency Based Training (CBT) as an alternative method of delivery for the polytechnics within a dynamic and progressive learning environment. Additionally, there was the perception of weak linkage between polytechnics and industry that lead to inadequate patterns of 
industrial attachment placement and internship training. CBT was introduced to improve the quality and relevance of Technical and Vocational Education and Training by equipping graduates with the required workplace and professional skills and promote a stronger working relationship with industry (COTVET 2006, NFP-NPT, Newsletter 2005).

The major reason for CBT reforms stems from the importance both governments and industry attach to the development of competences required in the labour market in order to significantly reduce the graduate unemployment rate, increase productivity and to achieve international competitiveness (Arguelles and Gonczi 2000). This is because empirically, CBT has proven to be the one major teaching and learning approach in TVET institutions with the capacity to reduce the gap between training and the labour market and achieve significant employability. Polytechnic education also emphasizes on the acquisition of certain important life skills in addition to academic knowledge. These are the key skills of communication and presentation as well as problem-solving skills. Evidently, these are intended to develop the students' confidence and critical faculties which are essential if they are to be effective contributors in society. Students are also afforded the opportunity to develop original and creative thinking and to behave as responsible young adults. At the turn of the century, the Malaysian Ministry responsible for Education aggressively embarked on a mission to develop students with soft skills programmes in order to produce high quality human capital, knowledgeable, competitive, with creative and innovative skills in line with industry requirements and social needs of the country (Siti Nor Habibah et al., 2012). This initiative is successfully being executed using CBT models in recognition of the added hurdles that disadvantaged youth face in the labour market.

This study is therefore significant in the sense that having churned out graduates through the CBT programme, it is only imperative that an academic assessment of their readiness for the job market is done. It is against this background that this need assessment study was undertaken. This study employed primary data in a unique context and categorically targeted students who have had the privilege of having gone through the CBT programme in two polytechnics, namely; Accra and Koforidua Polytechnics, now Accra and Koforidua Technical Universities respectively. Specifically, graduates who had studied the Plant engineering, Fashion Design and Textiles and Automobile Engineering programmes were used as respondents with the primary objective of assessing their readiness for the job market.

The remainder of the paper is organized as follows: The ensuing section briefly presents an overview of competency-based training and TVET and other relevant literature pertaining to the study. The next section 
essentially deals with the discussion of the methodology employed in the conduct of the research. Results are subsequently presented and discussed in section four. The article ends with drawn conclusions

\section{Competency-Based Training and TVET}

Technical and Vocational Education and Training (TVET) plays a significant role for the socio-economic development of any country to meet the challenges of skilled labour in the global market (Ansari \& Wu, 2013). Competency Based Training (CBT) as a method of delivery, thus signifies the practical aspect of technical and vocational training and relates theoretical knowledge to actual practice. It offers students the opportunity to gain hands-on experience and competencies on the job market. CBT as a technique uses an outcome based learning process which places the learner at the centre of the teaching and learning process in contrast to the traditional paradigm where the teacher is the centre of all activities. In many important ways, competency-based programmes have the potential to redistribute the power relationships between teachers and those taught (Betts and Smith, 1998). A major feature of the CBT programme is that, it ensures that learners acquires standardized knowledge and skills which are defined at each stage of the process and learners can only progress when they are able to satisfactorily demonstrate competence in knowledge and practical skills to an approved benchmark. These certifications, like others built to meet specific industry demand, are based solely on the learner's ability to demonstrate that, specific competencies have been attained, regardless of where or even how they were mastered (Voorhees, 2001). Thus, competency-based models ultimately rely on finitely measurable and quantifiable assessments. Accordingly, CBT programmes provide an improved form of delivery centered on the integration of acquired knowledge, professional and practical skills and attitude, coupled with a market-driven focus on the student (Afeti et al, 2003). In his narrative, Voorhees (2001) eulogized the concept of competency based teaching and learning as follows: 'the pathways to learning no longer lead automatically to traditional institutions of higher education. Instead they lead most directly to learning opportunities in which competencies are defined explicitly and delivery options are multiple. This new paradigm ultimately redefines the roles of faculty, institutions, and accreditors.' Voorhees (2001) also maintains that, the bridge between the traditional paradigm, which depends on traditional credit hour measures of student achievement and the learning revolution can be found in competency-based approaches.

Clearly, there are several advantages for students in competencybased training programmes. Because learning can be described and ultimately measured in techniques that are appreciated by both the teacher 
and the learner. The flexibility of competencies affords learners the opportunity to return to one or more competencies that have not been mastered in a learning process rather than facing the unwelcome prospect of repeating one or more traditional courses. Competencies also provide students with a clear map and the navigational tools needed to move expeditiously toward their goals (Voorhees, 2001). Additionally, the increasing globalization of the work force and job markets impose much more competitive skills and competencies on our graduates (Shakir, 2009).

According to Keeley (2007), soft skills play an integral role in advancing economic growth, especially in developing countries. These skills are largely grounded in communication ability, negotiation skills, flexibility and the capacity to adjust to new situations and negotiate challenging proposals. Schulz (2008), also emphasized that soft skills are imperative to any educational programme which aims to foster competencies which lead to the provision of a balanced life-style for its students, both during and after school. Ultimately, these skills constitute the basic requisites for effective social interaction and overall performance success. In an extensive research conducted, Kauffeld et, al. (2003) propose that hard and soft skills together constitute the unifying dimension of professional competence which allows an individual to achieve a goal-oriented and situational directedness with regard to working tasks. The findings of their study suggested that, the best indicator for the assurance of predictably higher success outcomes will depend on the level of harmonic integration of hard and soft skills.

\section{Competency-Based Training and Employability}

Employability results from several factors; a foundation of core skills, access to education, availability of training opportunities, motivation, ability and support to take advantage of opportunities for continuous learning, and recognition of acquired skills (Brewer, 2013). In a study conducted by Bar-Yam et al (2002), it was largely reported that, there has been a growing awareness of the necessity to change and improve the training and preparation of students for productive functioning in the continually changing and highly demanding environment in response to the rapidly changing and increasing complexity of today's digital world which present new challenges and put new demands on our education system.

Arguably, employability must be judged from the perspective of whether the training processes effectively equip students for lifetime learning and develop the self to be able to solve problems in life and employment (Knight and Yorke 2003, Van den Heijden 2005). Evidently, the training processes entailed in CBT equip students with competencies needed in their future professions and be able adapt to subsequent developments in their work (Wesselink and Wals 2011). 
According to Reid and Fitzgerald (2011), employability is principally about the state of being capable and able, and learning how to learn to be able to meet future challenges in a work environment. In his narrative Bagshaw (1997) offers a more dynamic view of employability which is not linked to possession of skills and competencies to survive in a work situation but requires flexibility and adaptability to be able to seek alternative employment in a changing world (as cited in Boahin et al. 2014). In his construct, Yorke (2007) perceives employability as being multi-faceted and characterized by an individual's ability to gain employment and be successful in their respective occupations and subsequent lifelong careers. This assertion is further linked with the job mastery and its relationship with the qualities of the study programme, on job training and ultimately the environment (Aamodt and Havnes 2008). Brewer (2013) was in agreement with these accounts when she outlined the components of employability to include the ability to continue to learn and adapt; read, write and compute competently; listen and communicate effectively; think creatively; solve problems independently; manage oneself at work; interact with co-workers; work in teams or groups; handle basic technology, lead effectively as well as follow supervision in addition to the essential vocational skills and technical competencies.

In her paper, Brewer (2013) further affirmed that employability goes beyond securing that first job. It is having the capacity to network and market oneself, navigate through a career and ultimately remain employable throughout life. This often requires the ability to probe, acquire new skills, identify and evaluate options, understand rights at work including the right to a safe and healthy work environment, adapt successfully to changing situations and the courage to innovate. Increasingly, the employability of job seeking graduates is significantly enhanced by improvement in transferable skills and competency-based training delivered through programmes that require work-place learning, including quality industrial attachment placements and internship training

\section{Methodology}

The study sought to conduct a detailed factor analysis of competency based trained graduates of Polytechnics and Technical Universities in Ghana. A Five-point Likert scale questionnaire designed and developed for the research were administered randomly to fifty-five respondents drawn from the population of interest for the study; that is, the pool of graduates who had passed through the CBT training programme. Fifteen of these students had majored in Plant Engineering, twenty had studied Fashion Design and Textiles as a combined major whilst the remaining twenty had majored in Automobile Engineering. Multivariate techniques of factor analysis and 
discriminant analysis were used in the study. Factor analysis technique is perhaps the most widely used multivariate technique, due mainly to its inherent robustness and the fact that it yields a considerable amount of information from a set of variables when properly employed. Particularly, exploring data for patterns, confirming hypotheses and reducing several variables to a more adaptable number. Relationships among sets of many interrelated variables are examined and represented in terms of a few underlying factors. Factor analysis is an interdependence technique in which an entire set of interdependent relationship is examined. Statistically, factor analysis is somewhat similar to multiple regression analysis, since each variable is expressed as a linear combination of underlying factors. The extent of variance a variable shares with all other variables included in the analysis is referred to as communality.

The communality of a variable $\left(X_{j}\right)$ is the proportion of the variance of $\left(X_{j}\right)$ explained by the $m$ common factors comm $\quad\left(X_{j}\right)=\sum_{i=1}^{m} \lambda_{i j}^{2}$

The variation among the variables is described in terms of a small number of common factors in addition to a unique factor for each variable. However, these factors are not overtly observed.

For an $m$ factor orthogonal and $n$ observed standardized variables, the factor model is represented as follows:

$$
\begin{aligned}
& X_{1}=\lambda_{11} F_{1}+\lambda_{12} F_{2}+\lambda_{13} F_{3}+\lambda_{14} F_{4}+\ldots+\lambda_{1 m} F_{m} \\
& X_{2}=\lambda_{21} F_{1}+\lambda_{22} F_{2}+\lambda_{23} F_{3}+\lambda_{24} F_{4}+\ldots .+\lambda_{2 m} F_{m} \\
& X_{3}=\lambda_{31} F_{1}+\lambda_{32} F_{2}+\lambda_{33} F_{3}+\lambda_{34} F_{4}+\ldots . .+\lambda_{3 m} F_{m} \\
& \prime \prime \\
& \quad \cdots \\
& X_{n}=\lambda_{n 1} F_{1}+\lambda_{n 2} F_{2}+\lambda_{n 3} F_{3}+\lambda_{n 4} F_{4}+\ldots . .+\lambda_{n m} F_{m}
\end{aligned}
$$

with the following assumptions: $\operatorname{corr}\left(F_{s}, X_{j}\right)=\lambda_{j s} \quad$ and $\operatorname{corr}\left(F_{s}, F_{r}\right)=0 \quad \forall s \neq r$

The procedure for conducting Factor Analysis is summarized in the following steps:

- Formulating the Problem: Problem formulation includes several tasks. First and foremost, the objectives of factor analysis is identified. The variables to be included in the factor analysis is also specified based on past research, theory and judgment of the researcher.

- Constructing the Correlation Matrix: The analytical process is based on a matrix of correlations between the variables. Valuable insights is gained 
from an examination of this matrix. For the factor analysis to be appropriate, the variables are then correlated.

- Determining the Method of Factor Analysis: Once it has been determined that factor analysis is indeed an appropriate technique for analyzing the data, an appropriate method is selected. The approach used to derive the weights or factor score coefficients differentiates the various methods of factor analysis. The two basic approaches are principal components analysis and common factor analysis. In principal component analysis, the total variance is the data considered. The diagonal of the correlation matrix consists of unities, and full variance is brought into the factor matrix. Principal components analysis is recommended when the primary concern is essentially to determine the minimum number of factors that will account for maximum variance in the data for use in subsequent multivariate analysis. The factors are called principal components. In common factor analysis, the factors are estimated based only on the common variance. Communalities are inserted in the diagonal of the correlation matrix. The method is appropriate when the primary concern is to identify the underlying dimensions and the common variance is of interest. This method is also known as principal axis available. Essentially, these include the methods of unweighted least squares generalized least squares, maximum likelihood, alpha method and alpha factoring.

- Determining the Number of Factors: It is possible to compute as many principal components as there are variables, but in doing so, no parsimony is gained. In order to summarize the information contained in the original variables, a smaller number of factors is extracted. The question is how many? Several procedures have been suggested for determining the number of factors. These include a priori determination and approaches based on eigenvalues, scree plots, percentage of variance accounted for, split half reliability and significance tests.

- Rotating Factors: An important output from factor analysis is the factor matrix also called factor pattern matrix. The factor matrix contains the coefficients used to express the standardized variables in terms of the factors. These coefficients or factor loadings, represent the correlations between the factors and the variables. A coefficient with a large absolute value indicates that the factor and the variable are closely related. The coefficients of the factor matrix can be used to interpret the factors. Although the initial or unrotated factor matrix indicated the relationship between the factors and individual variables, it seldom results in factors that can be interpreted, because the factors are correlated with many variables. Generally, through rotation, the factor matrix is transformed into a simpler one that is easier to interpret. 
- Calculating Factor Score: Following interpretation, factor scores are then calculated as required. Factor analysis thus, has its own stand-alone value. However, if the goal of factor analysis is to reduce the original set of variables to a marginal set of composite variables (factors) for use in subsequent multivariate analysis, it is useful to compute factor scores for each respondent. A factor is simply a linear combination of the original variables.

Incidentally, the final step in factor analysis, entails the determination of a model fit. A basic assumption underlying factor analysis is that the observed correlation between variables is attributed to common factors. Hence, the correlations between the variables could be deduced or reproduced from the estimated correlations between the variables and reproduced from the estimated correlations between the variables and the factors.

Basically, the differences between the observed correlations as estimated from the factor matrix and the reproduced correlations as estimated from the factor matrix, is examined to determine model fit. The main purpose of a discriminant function analysis is to predict group membership based on a linear combination of the predictor variables.

Essentially, the procedure is based on using a set of observations where both group membership and the values of the predictor variables are known. The end result of the procedure is a model that assigns cases into groups when the predictor variables are known. The second purpose of discriminant function analysis is an understanding of the data set. A thorough investigation of the resulting predicting model, ultimately gives an insight into the relationship between group membership and the variables used to predict group membership. The discriminant analysis model on the other hand involves linear combinations of the following form:

$$
\begin{aligned}
& D=b_{0}+b_{1} X_{1}+b_{2} X_{2}+b_{3} X_{3}+\ldots . .+b_{k} X_{k} \quad \text { where } \\
& D=\text { discriminant scores } \\
& b_{s}=\text { discriminant coefficients or weights } s=0,1,2,3, \ldots \text {, } \\
& X_{s}=\text { predictors or independent variables } s=1,2,3, \ldots \text {, }
\end{aligned}
$$

The coefficients, or weights $\left(b_{s}\right)$, are estimated so that the groups differ as much as possible on the values of the discriminant function. This occurs when the ratio of between group sums of squares to within-group sum of squares for the discriminant scores is at a maximum. Any other linear combination of the predictors results in a smaller ratio. In a study attributed to Moroney (1968), this system is not dependent on simple averaging of 
predictor variables, but applies weighting in the form of the coefficients $\left(b_{s}\right)$ in order to obtain the maximum discriminant.

Generally, the data for a discriminant function analysis is not standardized prior to the start of the analysis. This is because the outcome of a discriminant function analysis is not affected in any important way by the scaling of individual variables (Manly, 1994). The assumptions in discriminant analysis are that each of the groups is a sample from a multivariate normal population and all of the populations have the same covariance matrix. The role of these assumptions and the statistics just described could be better understood by examining the procedure of discriminant analysis.

Evidently, eigenvalues are significant in a discriminant function analysis process as they reflect the ratio of importance of the dimensions which classify cases of the dependent variable. Additionally, there is one eigenvalue for each discriminant function. For two-group or simple Discriminant analysis, there is always one discriminant function and one eigenvalue, which accounts for $100 \%$ of the explained variance. For three groups or multiple discriminant analysis, the eigenvalues are two. Thus for $n$ groups, there are $n-1$ number of eigenvalues. The eigenvalues are determined by solving the equation:

$$
\left|W^{-1} A-\gamma I\right|=0
$$

where the constant, $\quad \gamma$ is the eigenvalue, $W$ is the within group sums of squares and cross products matrix. Given the random sample, $x_{i 1}, x_{i 2}, \ldots . ., x_{i n_{i}}$ of size $n$, from a population with mean $\mu_{i}, i=1,2, \ldots . ., g ; g$ is the number of populations, and each $x_{i j}$ is an observation vector of $p$ components (number of variables).

The within group sums of squares and cross products matrix is expressed as

$\underline{W}=\sum_{i=1}^{g} \sum_{j=1}^{n_{i}}\left(x_{i j}-\overline{x_{i}}\right)\left(x_{i j}-\overline{x_{i}}\right)^{\prime} \quad$ where $i=1,2, \ldots \ldots g$ and $j=1,2, \ldots . n_{i}$

In addition, the between groups sums of squares and cross products (SSCP) matrix is given by the expression. $\underline{A}=\sum_{i=1}^{g} n_{i} x\left(\overline{x_{i}}-\bar{x}\right)\left(\overline{x_{i}}-\bar{x}\right)^{\prime}$

The eigen analysis also produces an eigenvector that is associated with each eigenvalue.

The eigenvectors are determined by solving the equation $\left(W^{-1} A-\gamma_{i} I\right) \hat{v}_{i}=0 ; \gamma_{i}$ is the eigenvalue corresponding to the $i^{\text {th }}$ canonical function, and $\hat{v}_{i}$ is the normalized eigenvector associated with the $i^{\text {th }}$ 
eigenvalue, $\underline{W}$ is the within-group SSCP matrix and $\underline{A}$ is the betweengroups SSCP matrix. Each solution, yields its own $\gamma$ and the set of $\hat{v}_{i}$ 's corresponds to one discriminant function. Another significant statistic is the (Model) Wilks' Lambda, $\lambda$. It is used to test the significance of the discriminant function as a whole.

A significant lambda means one can reject the null hypothesis that the groups have the same mean discriminant function scores and conclude that, the model is significantly discriminating. Moreover, the (Variable) Wilks' Lambda, $\lambda$ is used to test which independent variable contributes significantly in the discriminant function. The smaller the variable Wilk's lambda for an independent variable, the more that variable contributes to the discriminant function. Lambda varies from 0 to 1 , with 0 meaning group means differ. Thus the variable differentiates the groups and 1 signifies that, all group means are the same. The F test of Wilks's lambda shows which variables' contributions are significant. Wilk's Lambda follows the equation, $\lambda=\frac{|\underline{W}|}{|\underline{A}+\underline{W}|}$. Thus, the smaller the value of $\lambda$ the greater the probability that the null hypothesis is rejected and vice versa. In assessing the statistical significance of the Wilks' $\lambda$, it is converted into an F-ratio using the transformation

$F=\left(\frac{1-\lambda}{\lambda}\right) x\left(\frac{n_{1}+n_{2}-p-1}{p}\right)$; where $p$ is the number of variables for which the statistic is computed. Given that the null hypothesis is true, the Fratio follows an $\mathrm{F}$-distribution, with $p$ and $\left(n_{1}+n_{2}-p-1\right)$ degrees of freedom.

Beyond factor analysis, subsequent analysis is done with the discriminant technique, using the desire for graduates to set up on their own or otherwise as the response variable whilst the factors are the independent variables. Expectedly, Financial Support and Internship placements have high discriminating ability between the three groups of graduates; namely, the groups that constitute the dependent variable set. These are the cohorts of graduates with the following responses; "yes", "no" and "undecided" in reaction to the intrinsic desire to be trailblazers upon completion of their respective programmes of study.

\section{Findings}

Table 1: Correlations among Variables

$$
\begin{array}{llllllll}
x_{2} & x_{3} & x_{4} & x_{5} & x_{6} & x_{7} & x_{8} & x_{9} \\
& x_{10} & & & & & &
\end{array}
$$




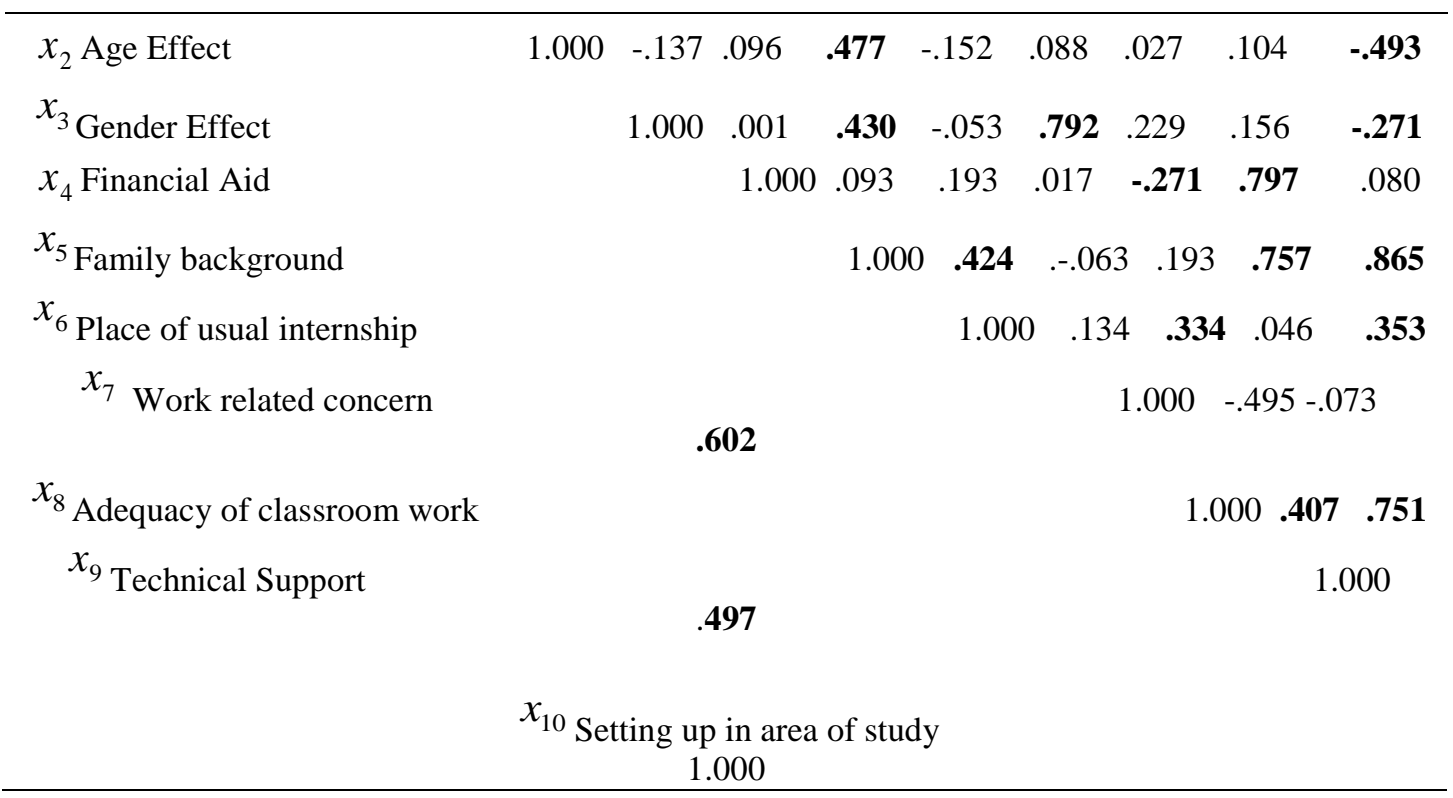

From Table 1 above, the assessment of the appropriateness of Factor analysis was done. The correlation matrix for the 9 job place variables were examined. Inspection of the correlation matrix revealed that 16 of the 45 correlations are significant at the 0.01 level of significance which provide an adequate basis for proceeding to an empirical examination of adequacy for factor analysis on both an overall basis and for each variable. Bolded values indicate correlation significant at the 0.01 significant level. Overall measure of sampling adequacy is 0.609 . Bartlet Test of Sphericity is 948.9 and the significance is 0.000 .

Table 2: Measures of Sampling Adequacy and Partial Correlations

\begin{tabular}{lcccccccc}
\hline & $x_{2}$ & $x_{3}$ & $x_{4}$ & $x_{5}$ & $x_{6}$ & $x_{7}$ & $x_{8}$ \\
$x_{9} \quad x_{10}$ & & & & & & & & \\
\hline$x_{2}$ Age Effect & .873 & & & & & & & \\
$x_{3}$ Gender Effect & .038 & .630 & & & & & & \\
$x_{4}$ Financial Aid & -.046 & -.060 & .527 & & & & & \\
$x_{5}$ Family background & -.082 & -.150 & -.150 & .890 & & & & \\
$x_{6}$ Place of usual internship & -.122 & .049 & .090 & .807 & .448 & & & \\
$x_{7}$ Setting up alone & -023 & -.157 & .067 & -.152 & .273 & .586 & & \\
$x_{8}$ Adequacy of classroom work &.- .006 & -.792 & .090 & -.088 & -.138 &.- .010 & .879 & \\
$x_{9}$ Technical Support & .124 & .091 & -.792 & -.118 & -.044 & -.542 & .145 & .859 \\
\hline
\end{tabular}




\begin{tabular}{llllllllll}
$x_{10}$ Setting up in area of study & .135 & .139 & .143 & -.054 & -.212 & -.029 & -.037 & - \\
$.037 \quad .443$ & & & & & & & & \\
\hline
\end{tabular}

In Table 2 above, the measures of sampling adequacy are on the diagonal whilst the partial correlations are in the off-diagonal. The Bartlett's measure finds that the correlations, when taken collectively are significant at the 0.01 level. Evidently, this test only indicates the presence of non-zero correlations.

Table 3: Results for the Extraction of Component Factor

\begin{tabular}{lccc}
\hline Component & Total & \% of Variance & Cumulative $\%$ \\
\hline 1 & 3.43 & 33.2 & 33.2 \\
2 & 2.55 & 23.1 & 56.3 \\
3 & 1.69 & 15.4 & 71.7 \\
4 & 1.16 & 9.9 & 81.6 \\
5 & 1.09 & 5.5 & 87.1 \\
6 & 0.40 & 5.0 & 92.1 \\
7 & 0.25 & 3.7 & 95.8 \\
8 & 0.20 & 3.0 & 98.8 \\
9 & 0.13 & 1.2 & 100.0 \\
\hline
\end{tabular}

In Table 3 above, the eigen values results for extracting the component factors among the variables is shown. By applying the latent root criterion of retaining factor with eigen values greater than 1.0, five factors are retained. The five factors retained 87.1 percent of the variance of the 9 variables deemed sufficient in terms of total variance explained.

Combining all these criteria together leads to retaining five factors; Age, Gender, Financial Aid, Family Background and Internship Placement were used for further analysis. The further analysis involves these retained factors as predictors and the readiness for graduates to be self-employed or otherwise or undecided as the three response categorical groups.

Predictably, a correlation matrix of the data predictor factors shows that at 5\% significant level only few pairs of independent variables correlated among themselves. The low correlation between the predictors suggests that multicollinearity is unlikely to be a problem. The Shapiro-Wilk test of Normality shows that most of the predictor variables exhibit normality at 5\%. The Levene Statistic of Age is the least whilst that of Gender is the largest. A one way ANOVA test of equality of means of predictors in the groups suggests that at 5\%, there is a significant differences between the means of Age, Gender, Financial aid, Family background and Internship Placement.

Table 4: Wilks Lambda

\begin{tabular}{lllll}
\hline Test of Function(s) & Wilks' Lambda & Chi-square & Df & Sig. \\
\hline
\end{tabular}


1 through 2

2
.147

.538
102.091

20.378
20

9
.000

.003

The first two canonical discriminant functions were used in the analysis. To test the null hypothesis of equal group centroids, both functions were considered simultaneously. As shown in Table 4, the value of Wilk's lambda for function 1 is 0.167 . This transforms to a chi-square of 102.091, with 20 degrees of freedom, which is significant beyond 0.05 levels. Thus, the two functions together significantly discriminate among the three groups.

Table 5: Eigenvalue

\begin{tabular}{ccccc}
\hline Function & Eigenvalue & \% of Variance & Cumulative \% & $\begin{array}{c}\text { Canonical } \\
\text { Correlation }\end{array}$ \\
\hline 1 & $2.819 \mathrm{a}$ & 83.3 & 83.3 & .859 \\
2 & $.567 \mathrm{a}$ & 16.7 & 100.0 & .602 \\
\hline
\end{tabular}

Since there are three groups, a maximum of two functions were extracted. The Eigenvalue associated with the first function is 2.819 , and this function accounts for $83.3 \%$ of the explained variance as shown in Table 3 . Because the Eigenvalue is large, the first function is more superior to the second function which accounts for only $16.7 \%$ of the variation with an Eigenvalue of 0.567 . The standardized canonical function coefficients in the appendix Table A1 indicate a large coefficients for Age, Gender and Financial. Expectedly, all the standardized canonical discriminant function coefficients are positive. The unstandardized discriminant function coefficients in the model reveal the contributions of the predictors in the discrimination amongst the groups. Examining the standardized discriminant function coefficients for function 1 , as evidently shown in the appendix Table A1, it is indicated that financial support has the largest discriminant coefficient with that of Gender being the least. Table A2 in the appendix shows the classification matrix or the prediction matrix. This contains the number of correctly classified and misclassified cases. The correctly classified cases appear on the diagonal. The classification results based on the analysis sample indicate that $84.6 \%$ in group 1 of the cases are correctly classified. When the classification analysis is conducted on the independent holdout sample; the result as indicated by the table shows that $75.0 \%$ of unselected original grouped cases in the same group are correctly classified. In the case of the validation sample, group 2 and 3 have $100 \%$ correctly classified cases. Evidently, from the analysis above and the unstandardized coefficients, the discriminant analysis model thus, becomes;

$$
D=-10.005+3.228 \text { Age }+0.516 \text { Gender }+1.459 \text { Family }+3.523 \text { Internship }+4.603 \text { Financial }
$$


It must be noted however, that these cases are assigned to groups based on their discriminant scores and an appropriate decision rule based on the group centroids in appendix Table A3. The interpretation of the discriminant weights or coefficients is similar to what pertains in multiple regression analysis. The value of the coefficient for a particular predictor largely depends on the other predictors included in the discriminant function.

Table A1: Standardized coefficients

\begin{tabular}{ccc}
\hline & \multicolumn{2}{c}{ Function } \\
& 1 & 2 \\
\hline Age & .516 & .457 \\
Gender & .134 & .176 \\
Financial & .657 & -.358 \\
Family & -.915 & .113 \\
Internship & 1.185 & -.164 \\
\hline
\end{tabular}

Table A2: Classification Matrix

\begin{tabular}{|c|c|c|c|c|c|c|c|}
\hline & & & \multirow[b]{2}{*}{$C L S$} & \multicolumn{3}{|c|}{ Predicted Group Membership } & \multirow[b]{2}{*}{ Total } \\
\hline & & & & 1 & 2 & 3 & \\
\hline \multirow[t]{6}{*}{ Cases Selected } & Original & Count & 1 & 11 & 1 & 1 & 13 \\
\hline & & & 2 & 0 & 27 & 0 & 27 \\
\hline & & & 3 & 0 & 1 & 7 & 8 \\
\hline & & $\%$ & 1 & 84.6 & 7.7 & .7 .7 & 100.0 \\
\hline & & & 2 & .0 & 100.0 & .0 & 100.0 \\
\hline & & & 3 & .0 & 12.5 & 87.5 & 100.0 \\
\hline \multirow[t]{6}{*}{ Cases Not Selected } & Original & Count & 1 & 3 & 1 & 0 & 4 \\
\hline & & & 2 & 0 & 6 & 0 & 6 \\
\hline & & & 3 & 0 & 0 & 2 & 2 \\
\hline & & $\%$ & 1 & 75.0 & 25.0 & .0 & 100.0 \\
\hline & & & 2 & .0 & 100.0 & .0 & 100.0 \\
\hline & & & 3 & .0 & 0 & 100 & 100.0 \\
\hline
\end{tabular}

Table A3

Group Centroids

\begin{tabular}{cc}
\hline Group & Centroid \\
\hline 1 & 1.090 \\
2 & 0.764 \\
3 & -4.817 \\
\hline
\end{tabular}




\section{Conclusion}

The Competency based curricula prominently dominate the programme landscape in most TVET institutions in Ghana, essentially to help graduates among other objectives, practically address problems in the economy particularly the high rate of unemployment. The analytical findings of the study revealed that Gender, Age, Financial Support, Family Background and Internship placements were the most dominant factors that influence the decision of graduates to become entrepreneurs or venture into some form of partnership or seek formal employment. The results also confirmed that a significant number of these graduates feel inadequate to establish their own businesses. It was also evident from the study that a greater segment of the graduate population who were competent enough to be trailblazers happen to come from the Fashion Design and Textile background, although all the respondents expressed the passionate desire to be employers in future and not job seekers. Financial Support and Internship placements have high discriminating ability between the three groups of students, namely; those who feel competent enough to be on their own immediately after school, the undecided cohort and those who do not have the conviction that they are competent enough to be on their own. In order to sufficiently address these inadequacies, the curricula of TVET training institutions should be enhanced to expose students to extensive entrepreneurial know-how skills to enable them build the needed capacity and self-confidence to establish their own setups and respond more promptly to emerging skills needs.

\section{References:}

1. Addy, M.E. (2008). Educational Reforms and the Sciences, Legon Observer, Vol 2 (1) p. 10, 20

2. Afeti G, Barfour A, Budu Smith, J (2003), Baseline Survey for the Introduction of Compentency Based Training: in Polytechnics, NCTE/JICA

3. Albaum, G., R. and D. Hawkins (1975), "Applying Discriminant Analysis to Unipolar Semantic Scaling Data" American Institute of Decision Sciences Western Meetings.

4. Arguelles, A. and Gonczi, A. (2000) Competency-based education and training: a world

5. perspective (Mexico: Conalep).

6. Ansari, B., \& Wu, X. (2013). Development of Pakistan's Technical and Vocational Education and Training (TVET): An Analysis of skilling Pakistan Reforms. Journal of Technical Education and Training (JTET), 52-64.

7. Bagshaw, M. (1997) Employability — creating a contract of mutual 
investment. Industrial

8. and Commercial Training, 27(6), 187-189.

9. Bar-Yam, M., Rhoades, K., Sweeney, L.B., Kaput, J. \& Bar-Yam, Y. (2002). Complex Systems

10. Perspectives on Education and the Education System, New England Complex Systems Institute, Cambridge, MA

11. Betts, M., and Smith, R. (1998). Developing the Credit-Based Modular Curriculum in Higher Education. Bristol, Pa.: Falmer Press, 1998.

12. Boahin, P., Eggink, J. \& Hofman, A. (2014) Competency based training in international perspective: comparing the implementation processes towards the achievement of employability, Journal of Curriculum Studies

13. Brewer, L. (2013). Enhancing youth employability: What? Why? and How? Guide to core work skills / Laura Brewer; International Labour Office, Skills and Employability Department. - Geneva: ILO, 2013.

14. COTVET Preparatory Technical Committee (CPTC). November, (2006) (Accra: JICA).

15. Evans, F. B. (1959), "Psychological and Objective Factors in the Prediction of Brand Choice: Ford vs. Chevrolet," Journal of Business 32 (October), pp.340-369

16. Friendly, M. (1991). Statistical Graphics for Multivariate Data. Paper presented at the SAS User's Group International Conference. New Orleans.

17. Gazette Notification. (1993). Polytechnic Law, P.N.D.C, L 321 (Publication No. A66/1,500/1/93). Accra: Ghana. Ghana Publishing Corporation.

18. Gazette Notification. (2007). Polytechnic Act, Act 745 (Publication No. GPC/A156/350/4/2007). Accra: Ghana. Ghana Publishing Corporation.

19. Guney, Y. (2009). Exogenous and Endogenous Factors Influencing Students' Performance in Undergraduate Accounting Modules. Accounting Education, 18 (1), 51-73.

20. Kauffeld, S., Grote, S., \& Frieling, E. (2003). Das KasselerKompetenz-Raster (KKR). [The

21. Kasseler-Competence-Pattern]. In J. Erpenbeck \& L. v. Rosenstiel (Eds.), Handbuch

22. Kompetenzmessung [Handbook for Measuring Professional Competence] (pp. 261-282).

23. Stuttgart: Schäfer-Poeschel Verlag.

24. Keeley, B. (2007). Human Capital: How What You Know Shapes Your

Life.

Paris:

OECD. 
http://www.oecd.org/insights/humancapitalhowwhatyouknowshapesy ourlife.htm.[Crossref], [Google Scholar]

25. Kendall, M. G. \& Stuart, A. (1966). The Advanced Theory of Statistics in Three volumes. (Volumes 3). Design and Analysis, and Time-Series. New York: Hafner Publishing Company.

26. Knight, P. T. and Yorke, M. (2003) Assessment, learning and employability (Maidenhead:

27. Society for Research into Education and Open University Press).

28. Miriam Bar-Yam, Kathleen Rhoades, Linda Booth Sweeney, Jim Kaput, and Yaneer Bar-Yam in Complex Systems Perspectives on Education and the Education System, New England Complex Systems Institute (2002)

29. Manly, B. F. J. (1994), Multivariate Statistical Methods. A Primer New York; (2 ${ }^{\mathrm{ND}}$ ED) Champman \& Hall.

30. Moroney, M. Y. (1968), Fact from Figures, Middlesex: Penguin Books Ltd.

31. Reid, C. and Fitzgerald, P. (2011) Assessment and employability. Available online at:

32. http://repos.hsap.kcl.ac.uk/content/m10058/1.5/, accessed January 13, 2012.

33. Schulz, B. (2008) The Importance of Soft Skills: Education beyond academic knowledge,

34. Journal of Language and Communication.

35. Salifu, A., Francesconi, G.N. and Kolavalli, S. (2010) 'A Review of Collective Action in

36. Rural Ghana', IFPRI Discussion Paper 00998, IFPRI, Washington.

37. Sharma, S. (1996). Applied Multivariate Techniques. Ney York: John Wiley \& Sons Publications.

38. Shakir, Rosalina. (2009). Soft skills at the Malaysian institutes of higher learning. Asia Pacific Education Review. September 2009, Volume 10, Issue 3, pp 309-315 Retrieved from http://link.springer.com/article/10.1007/s12564-009-9038-8

39. Skinner, C. E. (1945) Educational Technology, (Revised Edition). New York: Prentice-Hall Inc.

40. Stubbs, B. F. (1998) Students Performance Analysis. (MPhil dissertion, Bath University, 1998)

41. Retrieved March 21, 2009, from http://www.bstubbs.co.uk//mphil

42. Richard Voorhees (2001) New Directions for Institutional Research, no. 110, () John Wiley \& Sons, Inc.

43. Betts, M., and Smith, R. Developing the Credit-Based Modular Curriculum in Higher Education.

44. Bristol, Pa.: Falmer Press, 1998. 
45. Siti Nor Habibah, H., Mahanum, M. Z., Siti Nurhaida, K., Nortazi, S., Faizil, W., \& Anita Akmar, K. (2012). Company perception on the employability skills of industrial training students. Journal of Technical Education and Training (JTET), 1-8

46. Van der Heijden, B. I. J. M. (2005) No one has ever promised you a rose in garden. On

47. shared responsibility enhances strategies throughout careers. Inaugural address delivered

48. at the Open University of the Netherlands, Heerlen/Assen: Van Gorcum.

49. Voorhees, R. (2001) Competency-Based Learning Models: A Necessary Future. New Directions for Institutional Research, no. 110, Summer 2001C John Wiley \& Sons, Inc.

50. Wesselink, R. and Wals, E. J. (2011) Developing competence profiles for educators in

51. Environmental education in the Netherlands. Environmental Education Research, 17

52. (1), 69-90.

53. Yorke, M. (2007) Employability in Higher Education: What It is and what It is Not (Heslington:

54. Higher Education Academy, ESECT Series 1). 